\title{
Holonic Production System to Obtain Flexibility for Customer Satisfaction
}

\section{Gandolfo Dominici}

University of Palermo, Faculty of Economy, Italy

Email: gandolfodominici@unipa.it

Received December $3^{\text {rd }}, 2008$; revised December $10^{\text {th }}, 2008$; accepted December $15^{\text {th }}, 2008$.

\begin{abstract}
The Holonic Production System (HPS) can be a valid choice to overcome the problems of traditional production systems' architectures, thanks to its capability to adapt and react to changes in the business environment whilst being able to maintain systemic synergies and coordination. The HPS is made of holons seen as functional production units which are simultaneously autonomous and cooperative. Although the holonic approach could represent a valid solution in order to pursue the necessary levels of agility of production systems, they have been scarcely implemented in practice and even less studied from a business studies perspective. The purpose of this discussion paper is to show the benefits of further research on cases of implementation of HPS from a business organization studies perspective. Very little research on this topic has been done outside the field of business engineering and computer science; the study of this topic from a different perspective can shed the light on new aspects and new applications of the theory.
\end{abstract}

Keywords: holonic production systems, production agility, customer satisfaction

\section{Introduction}

Mass production showed its effectiveness in stable environments and with continuous growth trends ${ }^{1}$ until the end of the 80's. Since the beginning of the 90's, it has begun to show its weaknesses due to the growing instability of business environments and of systemic complexity. The spread of Internet made it possible for firms the use of a low cost, worldwide extended, informative infrastructure which can bring profound changes in the market. In mature markets it is necessary to supply a wide variety of products in order to adhere to the need of customers whose role has changed from "consumer" to "prosumer". Theses changes caused the shift from "mass production" to "mass-customisation". In order to fulfil these new needs for agility, it becomes unavoidable for firms to develop an extremely flexible production structure able to: a) duly react to the market environment's turbulences; $b$ ) survive production system changes through the adoption of new technologies; c) adapt to the uncertainties of production systems in such environments.

Neither hierarchical or heterarchical systems are able

\footnotetext{
${ }^{1}$ The hierarchical pattern on which mass production is founded presumes the steadiness of social, economic and technological factors.

${ }^{2}$ In 1972 McLuhan \& Nevitt [1] in "Take Today" suggested that electronic technologies would transform consumers into producers. Some years later, in 1980, the futurologist Alvin Toffler [2] in "The Third Wave" coined the term "prosumer", predicting the blurring of the distinction between producer and consumer due to the saturation of markets with standardized products which would have pushed towards the search for higher levels of differentiation and personalization of products.
}

to fulfil these requirements [3,4]. Hierarchical systems have a typically rigid structure which makes it very hard for them to react to turbulences in an agile way. Heterarchical systems are networks of elements with common aims in which each element shares with the others the same "horizontal" position of power and authority. Though heterarchical systems can easily adapt to environmental changes and turbulences, their control system cannot assure the high level of performance and the predictable organization behaviours needed for the industrial production of goods.

\section{Theoretical Framework}

The growing power of IT opened new possibilities in the worldwide arena and supplied management new and effective instruments for planning, budgeting, design and customer care. The central role of the customer thrived to the point that the supply chain has begun to be defined as the "demand" chain [5]. Literature on this topic shows several trends which manufacturing and supply chain systems have to adapt to [6,7]: a) the paradigm shift from mass production to semi-personalized production; $b$ ) the opening to collaboration with other agents in order to speed up production innovation and processes; c) the critical role of effective and efficient cooperation inside the network; d) understanding the problems connected to the implementation of a centralized control system between different entities with different information, experiences, activities, objectives and decisional authorities. 
These changes call for new organization structures. Traditional hierarchical systems show several inadequacies to work in these new business environments: a) they strongly limit the reconfiguration capacity, the reliability and the growth capacity of the organization [7]; b) their complexity grows together with the size of the organization [8]; c) communication among the elements of the system is strictly determined ex ante and vertically limited [9]; d) the structure's modules may not take initiatives, therefore reducing the system's readiness to react thus resulting not agile in turbulent environments environment [10]; e) the structure is expensive to build and to maintain. Heterachical systems do not have the limits of hierarchical systems, as they are able to obtain flexibility and adaptability to external stimuli. In heterachical systems every hierarchy is banned and power is given to the single "agents"3 of the system. Agents interact with their environment and with other agents according to their own attributes and aims. Control is based on negotiation due the lack of hierarchy.

In the field of artificial intelligence, the term agent is used to define the intelligent elements of a system who observe and act in the environment as entities capable of awareness and purposive behaviors; such agents must have the following attributes $[11,12]$ :

- Autonomy - they act without the help or guide of any superior entity;

- Social ability-they interact with other agents;

- Reactivity-they perceive their environment and respond rapidly to changes;

- Pro-activity-they are able to have initiative and specific behaviors for a specific scope.

For example, in a heterachical manufacturing system, the relation between the work station and supply orders is such that every supplier has direct contact with the work station in order to exploit all possible options to face unexpected fluctuations in supply and/or demand.

In spite of their agility, heterachical systems are not able to operate following predefined plans, hence their behavior is hardly predictable, increasing variability in systemic dynamics. Heterarchical structures work well in simple, non complex and homogeneous environments

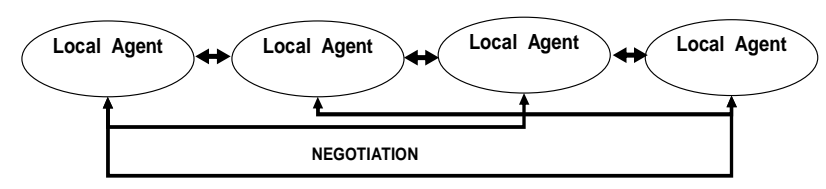

Figure 1. Heterachical control architecture

${ }_{3}^{3}$ Most of the system architectures based on agents are heterarchical. Nevertheless there are also agent based systems which do not adopt heterarchical control.

${ }^{4}$ Holistic scientific paradigm focusing on the study of Complex Adaptive Systems (C.A.S.) . with abundance of resources [10], while in complex environments they can bring to instability because of their unpredictability; moreover, with scarcity of resources, they are not able to act efficiently due to the lack of planning.

It is therefore necessary to conceptualize and implement a system able to assure both performance and reactivity at the same time. The answer to this challenge could come from the theories on living organisms and social organizations, which, if applied to the business, present a representation of the firm as a living system. The holonic paradigm emerges in this research stream, amidst the holistic ${ }^{4}$ approach and the vital systemic approach [13]. The holonic paradigm stems from the thoughts of Arthur Koestler [14] who underlined how complex systems can originate only if they are composed by stable and autonomous sub-systems, which are able to survive turbulences and, at the same time, can cooperate forming a more complex system. Koestler underscores that analyzing both the biological and the physical universe shows that, it is necessary to take into account the relations between the whole and the part of the entities we observe. To understand the abearance of the world, according to Koestler, is not enough to study atoms, molecules, cells individuals or systems as independent entities, but it is crucial to consider such unities as simultaneously part of a larger whole; in other words, we have to consider it as a holon. The term holon is a combination of the ancient Greek "Ö ${ }_{0} \varsigma$ " with the meaning of "whole" and the suffix "ôv" meaning "entity" or part; thus the whole is made of parts which unlike atoms are also entities. The holon is, indeed, a whole which includes, simultaneously, the elements or the subparts which form it and give it structural and functional meaning. Holons act as intelligent, autonomous and cooperative entities working together inside temporary hierarchies called "holarchies". A holarchy is a hierarchy of self-regulating holons working, in coordination with their environment, as autonomous wholes which are hierarchically superior to their own parts and, at the same time, are parts dependent by the control of superior levels. Figure 2 shows the general relationship between holon and holarchy.

Holons of the same level process elements and information coming from lower level holons and they transfer the results to higher level ones for further processing. Processes of holons belonging to level ' $n$ ' hence originate from

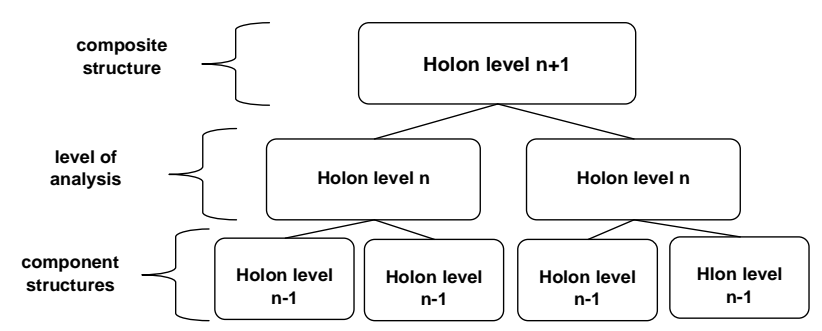

Figure 2. Holons and holarchies 
process of ' $n-1$ ' level subordinated holons and at the same time are the input for the processes of ' $n+1$ ' superior holons. $[15,16]$. The strength of the holonic approach resides in the concept of holarchy, which allows the development and implementation of extremely complex systems which are able to use resources efficiently, are resilient to disturbances and, at the same time, adaptable to changes of the environment. What makes the holonic system extremely effective in turbulent environments is that, inside a holarchy, holons are able to dynamically create and change hierarchies and also to participate to different hierarchies simultaneously. The holonic system can therefore be defined as a global and organized entity made of interrelations among highly self-regulating operative units which are able to cooperate with each other, keeping their autonomy, seeking shared results and common aims. It is possible to find the three pillars of holonic systems [17]:

1) the shared-value system in the organization allows the spontaneous and continuous interaction among groups of people who are far from each other and are not linked by legal or ownership ties, in order to take advantage of the economies of cooperation and of the increased stability of the system. Examples of shared value systems are some of the elements of lean production, that are often embedded in the company's vision, such as the principle of continuous improvement (kaizen);

2) the distributed network information system which is the neural sub-system [18] supporting real time supply of information between operating units which consents the pursuit of maximum income by better exploiting the coming business opportunities;

3) the autonomous distributed hierarchy which is based on the ability of each autonomous part to become leader according to requirements of specific situations caused by the turbulent changes in the environment. Every entity is able to directly interact with other entities without mediation. Due to this property in a holonic system every holon has potentially the same importance and the same responsibility; the involvement of a holon as operative unit is based on its knowledge and competencies and is not a consequence of predefined leadership.

\section{The Holonic Production System}

The Holonic Production System (HPS) can be a valid choice to overcome the problems of traditional production systems' architectures, thanks to its capability to adapt and react to changes in the business environment whilst being able to maintain systemic synergies and coordination. The HPS is made of holons seen as functional production units which are simultaneously autonomous and cooperative. These holons can be represented as networked agents which define different levels of a system [19].

Every element represented in Figure 4 is a holon (work cell, factory, firm, supply chain). At the supply chain level the interaction among firms, their suppliers and their clients takes place. It is possible to determine a subsystem for each firm in the supply chain level, this subsystem is an enterprise level holon. In the enterprise there is cooperation among factories and sales departments. Inside each factory there are several working cells which interact with each other; the working cell is the basic level of the holarchy described which is self-controlled by the interaction among men and machines [20].

\section{Cases of Application of Theory and Further Possible Developments of Research}

Although the holonic approach could represent a valid solution in order to pursue the necessary levels of agility of production systems, they have been scarcely implemented in practice and even less studied from a business studies perspective. Furthermore few studies of implementation of holonic-like systems can be found in the literature. Shen [21] noted that IBM has been one of the first firms to adopt a system based on intelligent agents to avoid bottlenecks and smooth production. Jennings \& Bussman [22] developed a way to implement a standard modules system, where each module is flanked by an

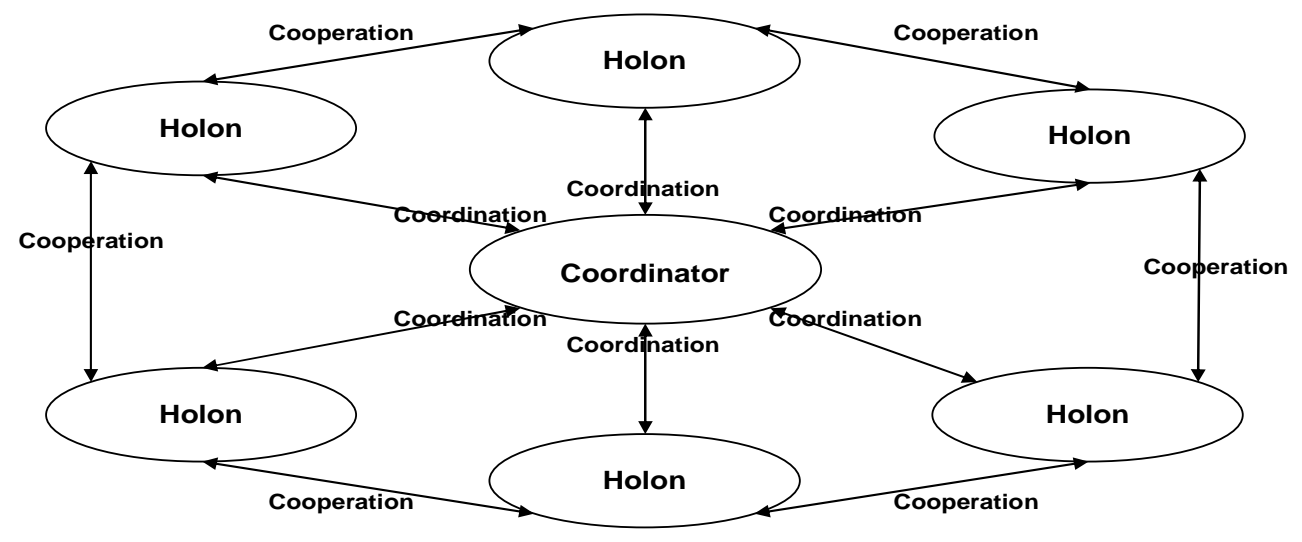

Figure 3. Architecture of an autonomous distributed system 


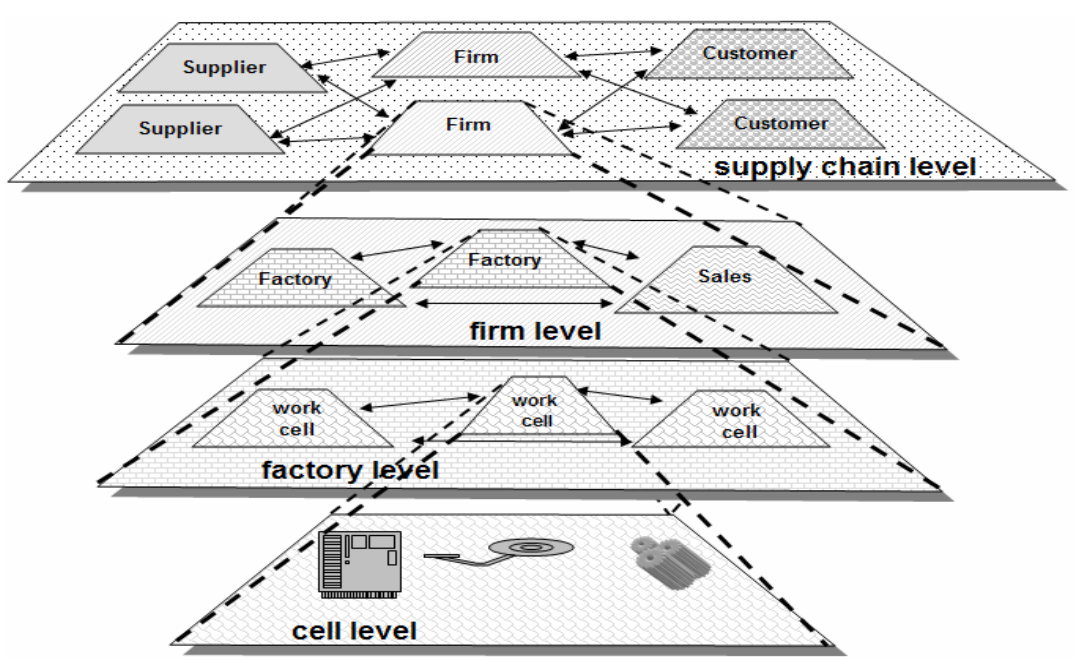

Figure 4. Production holarchy and relation among the different holon-levels

intelligent agent in order to compose a holon which becomes the building block of the system; this system has been tested by Daimler-Chrysler in order to evaluate its resilience of the system. The result obtained was of $99,7 \%$ of the theoretical optimum and the system has been adopted in the Factory of Stuttgart-Untertürkheim in Germany.

The purpose of these notes is to show the benefits of further research on cases of implementation of HPS from a business organization studies perspective. Very little research on this topic has been done outside the field of business engineering and computer science; the study of this topic from a different perspective can shed the light on new aspects and new applications of the theory.

The HPS is surely not easy to implement in a real factory, nevertheless a step-by-step approach for the introduction of this system in those industries where the need for flexibility goes together with the scarcity of resources and margins, can become the way for the factory of the XXI century.

\section{REFERENCES}

[1] M. McLuhan and B. Nevitt, "Take today: The executive as dropout. B. J. Harcourt, 1972.

[2] A. Toffler, "The third wave," Bantam, 1980.

[3] D. M. Dilts, N. P. Boyd, and H. H. Whorms, "The evolution of control architectures for automated manufacturing systems," Journal of Manufacturing Systems 10(1), pp. 79-93, 1991.

[4] T. J. Crowe and E. J. Stahlman, "A proposed structure for distributed shopfloor control," Integrated Manufacturing Systems 6 (6), pp. 31-36, 1995.

[5] R. Blackwell and K. D. Blackwell, "The century of the consumer: Converting supply chains into demand chains," Supply Chain Management Review, pp. 22-32, 1999.

[6] F. Frederix, "From production to a product perspective," New Industrial Scenario, In Yoon S. et all. Evolution of Supply Chain Management, Symbiosis of Adaptive Value Networks and ICT, Kluwer Academic Publishers, Norwell, 2004.

[7] L. Gou, P. B. Luh, and Y. Kyoya, "Holonic manufacturing scheduling: Architecture, cooperation mechanism, and implementation," Computers in Industry, 37 (3), pp. 213-231, 1998.

[8] J. Hatvany, "Intelligence and cooperation in heterarchic manufacturing systems," Robotics \& Computer-Integrated Manufacturing, 2 (2), pp. 101-104, 1985.

[9] H. V. Brussel, L. Bongaerts, J. Wyns, P. Valckenaers, and T. V. Ginderachter, "A conceptual framework for Holonic manufacturing: Identification of manufacturing holons," Journal of Manufacturing Systems, 18 (1), pp. 35-52, 1999.

[10] P. Valckenaers, E. Bonneville, H. V. Brussel, L. Bongaerts, and J. Wyns, "Results of the holonic control system benchmark at the kuleven," Proceedings of CIMAT, pp. 128-133, 1994.

[11] T. Moyaux, B. Chaib-draa, and S. D'Amours, "Supply chain management and multiagent systems: An overview,” In B. Chaib-draa, J. P. Müller (editor), Multiagent based Supply Chain Management. Springer, 2006.

[12] M. Paoloucci and R. Sacile, "Agent-based manufacturing and control systems," CRC Press, 2005.

[13] G. M. Golinelli, L'approccio sistemico al governo dell' impresa-L'impresa sistema vitale Vol. 1. CEDAM, Italy, 2000.

[14] A. Koestler, "The ghost in the machine," Arkana, 1967.

[15] M. Mesarovic, D. Macko, and Y. Takahara, "Theory of hierarchical, multi-level systems," Academic Press, 1970.

[16] P. Mella, "La Rivoluzione Olonica: Oloni, olarchie e reti oloniche," Il fantasma del kosmos produttivo, FrancoAngeli, Italy, 2005.

[17] C. Saccani, "Il Sistema Olonico," Sistemi\&Impresa, 2, pp. 29-45,1996.

[18] M. A. Arbib, "The handbook of brain theory and neural networks," MIT Press, Boston, 1995.

[19] M. Ulieru and M. Cobzaru, "Building holonic supply chain management systems: An e-logistics application for the telephone manufacturing industry, IEEE Transactions on Industrial Informatics 1 (1), pp. 18-30, 2005.

[20] G. Dominici, "Il contesto istituzionale nipponico e l'evoluzione della "lean production," Aracne, Roma, Italy, 2007.

[21] W. Shen, "Distributed manufacturing scheduling using intelligent agents," IEEE Intelligent Systems, pp. 88, 2002.

[22] N. R. Jennings and S. Bussmann, "Agent-based control systems," Why are they suited to engineering complex systems?. IEEE Control Systems Magazine, 61, 2003. 